Vietnam Journal of Mechanics, VAST, Vol.30, No.2 (2008), pp. $112-124$

\title{
ANALYSIS OF STIFFENED LAMINATED COMPOSITE PLATES BY FINITE ELEMENT BASED ON HIGHER-ORDER DISPLACEMENT THEORY
}

\author{
Tran Ich Thinh \\ Hanoi University of Technology \\ Tran Huu Quoc \\ Vietnam Academy of Science and Technology
}

\begin{abstract}
In this paper, authors use a finite element model based on higher-order displacement plate theory for analysis of stiffened laminated composite plates. Transverse shear deformation is included in the formulation making the model applicable for both moderately thick and thin composite plates. The plate element used is a nine-noded isoparametric one with nine degrees of freedom at each node. The stiffness of stiffener is reflected at all nine nodes of plate element in which it is placed. Accordingly, the stiffeners can be positioned anywhere within the place element. Free vibration and deflection of stiffened laminated composite plates are carried out, and results are compared with existing analytical and other solutions.
\end{abstract}

\section{INTRODUCTION}

Stiffened laminated composite plates are widely used in many industrial structures such as aerospace structures, road bridges, ship hull, etc. due to their high strength to weight ratios.

In order to analyse stiffened laminated composite plates, some authors used finite difference method [1], Rayleigh-Ritz method and finite element method. In [2], Ahmadian M. T. and Zangeneh M. S. used the combination of plate super elements and beam super elements, the plate and beam elements having 55 and 18 degrees of freedom respectively. Olson and Hazel1 [3] have presented results from a theoretical and experimental comparison study on the vibration characteristics of all clamped and eccentrically stiffened isotropic plates. They used a triangular finite element in the calculations. Koli [4] developed a 9-noded rectangular plate element and 3-noded beam element; the beams are placed along the plate nodal lines. Biswal and Ghosh [5] used 4-noded rectangular elements with seven degrees of freedom at each node for analysis of stiffened plates. Gangadhara Prusty [6] studied linear static analysis of composite hat-stiffened laminated shells using 8-noded rectangular plate element and 3-noded beam element. In [11], a model based on third-order displacement theory had been studied to carry out some problems such as free vibration and deflection but the beam element hadn't been placed along the plate nodal lines and it makes difficult in meshing.

This paper presents the development of a stiffened composite plate element model using a nine-noded plate element and a beam whose displacements have been interpolated by the displacements of plate element. The model is based on a higher-order displacement theory which eliminates the need to use shear correction coefficients and make the 
model applicable for both thick and thin stiffened composite plates. The stiffeners can be positioned anywhere within the plate element. Free vibration and deflection of stiffened laminated plates are carried out, and results are compared with existing analytical and other solutions.

\section{FINITE ELEMENT FORMULATION}

The geometry of the problem is similar to that shown in Fig.1. A stiffened plate is composed of a plate element and a number of stiffener elements placed in the plate element. Both plate and stiffeners are made up of laminated composites.

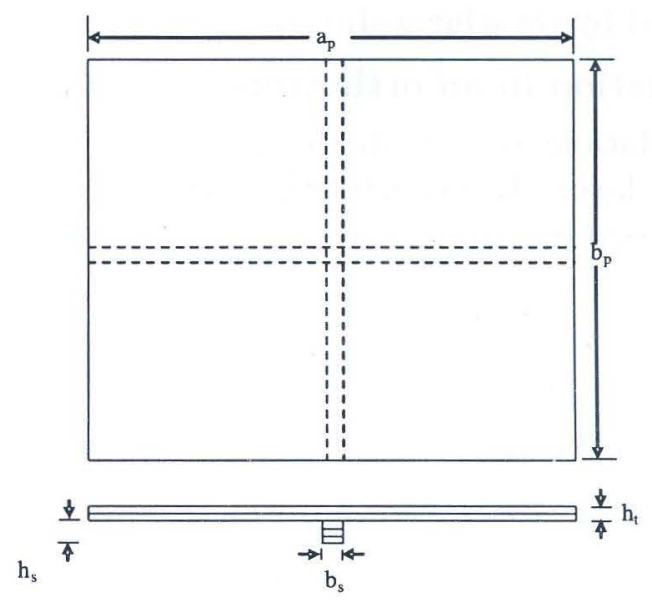

Fig. 1. Laminated stiffened composite plates

\subsection{Displacement field}

The assumed displacement field at time $t$ (Fig. 1) for the numerical finite element model is a third-order expansion in the thickness coordinate for the in-plane displacements and a constant transverse displacement.

Plate:

$$
\begin{aligned}
& U_{p}(x, y, z, t)=u_{0 p}(x, y, t)+z \theta_{x p}(x, y, t)+z^{2} u_{0 p}^{*}(x, y, t)+z^{3} \theta_{x p}^{*}(x, y, t) \\
& V_{p}(x, y, z, t)=v_{0 p}(x, y, t)+z \theta_{y p}(x, y, t)+z^{2} u_{0 p}^{*}(x, y, t)+z^{3} \theta_{y p}^{*}(x, y, t) \\
& W_{p}(x, y, z, t)=w_{0 p}(x, y, t)
\end{aligned}
$$

This displacement field can be represented in matrix form as:

$$
\begin{aligned}
& \{U\}=[Z]\{q\}, \quad\{U\}=\{U V W\}^{T} \\
& {[Z]=\left[\begin{array}{ccccccccc}
1 & 0 & 0 & z & 0 & z^{2} & 0 & z^{3} & 0 \\
0 & 1 & 0 & 0 & z & 0 & z^{2} & 0 & z^{3} \\
0 & 0 & 1 & 0 & 0 & 0 & 0 & 0 & 0
\end{array}\right],} \\
& \{q\}=t\left\{u_{0} v_{0} w_{0} \theta_{x} \theta_{y} u_{0}^{*} v_{0}^{*} \theta_{x}^{*} \theta_{y}^{*}\right\}
\end{aligned}
$$

where $u_{0}, v_{0}, w_{0}$ displacements of a generic point in the middle plane of the laminate are referred to the local axes, $x, y, z$, directions and $\theta_{x}, \theta_{y}$ are the rotations of the normal 
to the middle plane about $\mathrm{x}$ axis and $\mathrm{y}$ axis. The functions $u_{0}^{*}, v_{0}^{*}, \theta_{x}^{*}, \theta_{y}^{*}$ are higher order terms in the Taylor series expansion, defined also in the middle plane.

The $x y$-plane is taken as the plate mid-plane and the $z$-axis is its upward normal. For $x$-directional stiffener:

$$
\begin{aligned}
& U_{x s}(x, z, t)=u_{0 x s}(x, t)+z \theta_{x s}(x, t)+z^{2} u_{0 x s}^{*}(x, t)+z^{3} \theta_{x s}^{*}(x, t) \\
& W_{x s}(x, z, t)=w_{0 x s}(x, t)
\end{aligned}
$$

The $x$-axis is taken along the stiffener center line and the $z$-axis is its upward normal. The $x$-directional stiffener is the basic stiffener; other directional stiffener will be obtained by rotating $x$-directional stiffener about $z$-axis by $\alpha$ angles. In special case, $y$-directional stiffener will be obtained by rotating $x$-directional stiffener about $z$-axis by $90^{\circ}$.

\subsection{Stress-strain relation in an orthotropic lamina}

The stress-strain relations of a laminate of $n$ layers are defined based on the stressstrain relations in each layer. The constitutive equations, in terms of material axes, for $k^{\text {th }}$ orthotropic layer, assuming a state of plane stress and a linear elastic material, are written as

$$
\sigma_{k}=Q_{k} \varepsilon_{k} \quad \text { or }\left\{\begin{array}{l}
\sigma_{1} \\
\sigma_{2} \\
\tau_{12} \\
\tau_{13} \\
\tau_{23}
\end{array}\right\}=\left[\begin{array}{lllll}
Q_{11} & Q_{12} & 0 & 0 & 0 \\
Q_{21} & Q_{22} & 0 & 0 & 0 \\
0 & 0 & Q_{33} & 0 & 0 \\
0 & 0 & 0 & Q_{44} & 0 \\
0 & 0 & 0 & 0 & Q_{55}
\end{array}\right]\left\{\begin{array}{l}
\varepsilon_{1} \\
\varepsilon_{2} \\
\gamma_{12} \\
\gamma_{13} \\
\gamma_{23}
\end{array}\right\}
$$

where $\sigma_{1}, \sigma_{2}, \tau_{12}, \tau_{13}, \tau_{23}$ are the normal and shearing stresses components, $\varepsilon_{1}, \varepsilon_{2}, \gamma_{12}, \gamma_{13}, \gamma_{23}$ are the normal and distortion strains, and $Q_{k}$ is the elasticity matrix, whose non-zeros elements are given by

$$
\begin{aligned}
& Q_{11}=E_{1} /\left(1-\nu_{12} \nu_{21}\right), \quad Q_{12}=\nu_{12} E_{1} /\left(1-\nu_{12} \nu_{21}\right), \quad Q_{22}=E_{2} /\left(1-\nu_{12} \nu_{21}\right) \\
& Q_{33}=G_{12}, \quad Q_{44}=G_{13}, \quad Q_{55}=G_{23}
\end{aligned}
$$

where $E_{1}$ and $E_{2}$ are the Young's modulis, referred to 1 and 2 material axes, respectively, $G_{12}, G_{13}, G_{23}$ are the transverse shear modulis in plane 1-2, 1-3, 2-3, respectively, and $\nu_{12}$ is major Poisson's ratio, related to $\nu_{21}$ through $E_{1} \nu_{12}=E_{2} \nu_{21}$.

The stress-strain relations referred to the reference axes of the laminate $(x, y, z)$, for the orthotropic layer whose fibers are orientated of and angle $\alpha_{L}$ to the $x$ axis, are given by

$$
\begin{aligned}
& \bar{\sigma}_{k}=\bar{Q}_{k} \bar{\varepsilon}_{k}, \quad \bar{\sigma}_{k}=\left\{\begin{array}{ccccc}
\sigma_{x} & \sigma_{y} & \sigma_{x y} & \tau_{x z} & \tau_{y z}
\end{array}\right\}^{T}, \\
& \bar{\varepsilon}_{k}=\left\{\begin{array}{llllll}
\varepsilon_{x} & \varepsilon_{y} & \gamma_{x y} & \gamma_{x z} & \gamma_{y z}
\end{array}\right\}^{T},
\end{aligned}
$$

where the elements of matrix $\bar{Q}_{k}$ are given in [10].

The kinematics relations for linear elasticity the strain $\bar{\varepsilon}$ associated with displacement field in (1) are represented as:

$$
\begin{aligned}
\bar{\varepsilon}_{k}=\left\{\begin{array}{ccccccccc}
\frac{\partial u_{0}}{\partial x} & \frac{\partial v_{0}}{\partial y} & \frac{\partial v_{0}}{\partial x}+\frac{\partial u_{0}}{\partial y} & \frac{\partial u_{0}^{*}}{\partial x} & \frac{\partial v_{0}^{*}}{\partial y} & \frac{\partial v_{0}^{*}}{\partial x}+\frac{\partial u_{0}^{*}}{\partial y} & \frac{\partial \theta_{x}}{\partial x} & \frac{\partial \theta_{y}}{\partial y} & \frac{\partial \theta_{x}}{\partial y}+\frac{\partial \theta_{y}}{\partial x} \\
\frac{\partial \theta_{x}^{*}}{\partial x} & \frac{\partial \theta_{y}^{*}}{\partial y} & \frac{\partial \theta_{y}^{*}}{\partial x}+\frac{\partial \theta_{x}^{*}}{\partial y} & \theta_{x}+\frac{\partial w_{0}}{\partial x} & \theta_{y}+\frac{\partial w_{0}}{\partial y} & 2 u_{0}^{*} & 2 v_{0}^{*} & 3 \theta_{x}^{*} & 3 \theta_{y}^{*}
\end{array}\right\}^{T} .
\end{aligned}
$$


Integrating the stresses through the laminate thickness, one obtains the resultant forces and moments acting on the lamina

$$
\begin{aligned}
& {\left[N, N^{*}\right]=\left[\begin{array}{ll}
N_{x}, & N_{x}^{*} \\
N_{y}, & N_{y}^{*} \\
N_{x y}, & N_{x y}^{*}
\end{array}\right]=\sum_{k=1}^{n} \int_{Z_{k}}^{Z_{k+1}}\left[\begin{array}{l}
\sigma_{x} \\
\sigma_{y} \\
\sigma_{x y}
\end{array}\right]\left[1, z^{2}\right] d z ;} \\
& {\left[M, M^{*}\right]=\left[\begin{array}{ll}
M_{x}, & M_{x}^{*} \\
M_{y}, & M_{y}^{*} \\
M_{x y}, & M_{x y}^{*}
\end{array}\right]=\sum_{k=1}^{n} \int_{Z_{k}}^{Z_{k+1}}\left[\begin{array}{l}
\sigma_{x} \\
\sigma_{y} \\
\sigma_{x y}
\end{array}\right]\left[z, z^{3}\right] d z} \\
& {\left[Q, S, Q^{*}\right]=\left[\begin{array}{lll}
Q_{x}, & S_{x}, & Q_{x}^{*} \\
Q_{y}, & S_{y}, & Q_{y}^{*}
\end{array}\right]=\sum_{k=1}^{n} \int_{Z_{k}}^{Z_{k+1}}\left[\begin{array}{l}
\tau_{x y} \\
\tau_{y z}
\end{array}\right]\left[1, z, z^{2}\right] d z}
\end{aligned}
$$

So, we obtain the equation $\quad\{\bar{N}\}=[D]\{\bar{\varepsilon}\}$, where $\{\bar{N}\}=\left\{N_{x}, N_{y}, N_{x y}, N_{x}^{*}, N_{y}^{*}, N_{x y}^{*}, M_{x}, M_{y}, M_{x y}, Q_{x}, Q_{y}, S_{x}, S_{y}, Q_{x}^{*}, Q_{y}^{*}\right\}$

$$
\begin{aligned}
& {[D]_{18 \times 18}=\left[\begin{array}{ccccccc}
A & C & B & D & 0 & 0 & 0 \\
C & E & D & F & 0 & 0 & 0 \\
B & D & C & E & 0 & 0 & 0 \\
D & F & E & G & 0 & 0 & 0 \\
0 & 0 & 0 & 0 & A_{p s} & B_{p s} & C_{p s} \\
0 & 0 & 0 & 0 & B_{p s} & C_{p s} & D_{s s} \\
0 & 0 & 0 & 0 & C_{p s} & D_{p s} & E_{p s}
\end{array}\right]} \\
& {\left[\begin{array}{ll}
A & C \\
C & E
\end{array}\right]=\sum_{k=1}^{n}\left[\begin{array}{cc}
H_{1} & H_{3} \\
H_{3} & H_{5}
\end{array}\right] \bar{Q}_{i j} ; \quad\left[\begin{array}{cc}
B & D \\
D & F
\end{array}\right]=\sum_{k=1}^{n}\left[\begin{array}{cc}
H_{2} & H_{4} \\
H_{4} & H_{6}
\end{array}\right] \bar{Q}_{i j} ;} \\
& {\left[\begin{array}{ll}
C & E \\
E & G
\end{array}\right]=\sum_{k=1}^{n}\left[\begin{array}{ll}
H_{3} & H_{5} \\
H_{5} & H_{7}
\end{array}\right] \bar{Q}_{i j} ;\left[\begin{array}{ccc}
A_{p s} & B_{p s} & C_{p s} \\
\text { symm } & C_{p s} & D_{p s} \\
s y m & E_{p s}
\end{array}\right]=\sum_{k=1}^{n}\left[\begin{array}{lll}
H_{1} & H_{2} & H_{3} \\
& H_{3} & H_{4} \\
& & H_{5}
\end{array}\right] \bar{Q}_{l m}}
\end{aligned}
$$

where $H_{j}=\left(z_{k+1}^{h}-z_{k}^{h}\right) / h$ with $i, j=1,2,3$ and $l, m=4,5 ; h=1,2,3,4,5,6,7 . n$ is number of layers.

Similarly in the local axis of stiffener we obtain:

$$
\left[D_{s}\right]_{7 \times 7}=\left[\begin{array}{ccccccc}
A_{s} & C_{s} & B_{s} & D_{s} & 0 & 0 & 0 \\
C_{s} & E_{s} & D_{s} & F_{s} & 0 & 0 & 0 \\
B_{s} & D_{s} & C_{s} & E_{s} & 0 & 0 & 0 \\
D_{s} & F_{s} & E_{s} & G_{s} & 0 & 0 & 0 \\
0 & 0 & 0 & 0 & A_{s s} & B_{s s} & C_{s s} \\
0 & 0 & 0 & 0 & B_{s s} & C_{s s} & D_{s s} \\
0 & 0 & 0 & 0 & C_{s s} & D_{s s} & E_{s s}
\end{array}\right]
$$

where $\left[A_{s}, B_{s}, C_{s}, D_{s}, E_{s}, F_{s}, G_{s}\right]=\sum_{k=1}^{n}\left[H_{1}, H_{2}, H_{3}, H_{4}, H_{5}, H_{6}, H_{7}\right] \bar{Q}_{11}$ $\left[A_{s s}, B_{s s}, C_{s s}, D_{s s}, E_{s s}\right]=\sum_{k=1}^{n}\left[H_{1}, H_{2}, H_{3}, H_{4}, H_{5}\right] \bar{Q}_{44}$ 


\subsection{Finite element formulation}

Using 9 noded isoparametric finite element with 9 degrees of freedom per node, the continuum displacement vector within the element can be expressed in terms of nodal displacements

$$
q=\sum_{i=1}^{9} N_{i}(\xi, \eta) q_{i} \quad \text { where } q_{i}=\left\{\begin{array}{lllllllll}
u_{0 i} & v_{0 i} & w_{0 i} & \theta_{x i} & \theta_{y i} & u_{0 i}^{*} & v_{0 i}^{*} & \theta_{x i}^{*} & \theta_{y i}^{*}
\end{array}\right\},
$$

$N_{i}(\xi, \eta)$ are the shape functions which were given in $[11] ; \xi, \eta$ are the natural co-ordinates. The generalized strain vector at any point, is given by $\bar{\varepsilon}_{k}=\sum_{i=1}^{9} B_{i} q_{i}$, where

$$
B_{i}=\left[\begin{array}{ccccccccc}
\frac{\partial N_{i}}{\partial x} & 0 & 0 & 0 & 0 & 0 & 0 & 0 & 0 \\
0 & \frac{\partial N_{i}}{\partial y} & 0 & 0 & 0 & 0 & 0 & 0 & 0 \\
\frac{\partial N_{i}}{\partial y} & \frac{\partial N_{i}}{\partial x} & 0 & 0 & 0 & 0 & 0 & 0 & 0 \\
0 & 0 & 0 & 0 & 0 & \frac{\partial N_{i}}{\partial x} & 0 & 0 & 0 \\
0 & 0 & 0 & 0 & 0 & 0 & \frac{\partial N_{i}}{\partial y} & 0 & 0 \\
0 & 0 & 0 & 0 & 0 & \frac{\partial N_{i}}{\partial y} & \frac{\partial N_{i}}{\partial x} & 0 & 0 \\
0 & 0 & \frac{\partial N_{i}}{\partial x} & 0 & 0 & 0 & 0 & 0 & 0 \\
0 & 0 & 0 & \frac{\partial N_{i}}{\partial y} & 0 & 0 & 0 & 0 & 0 \\
0 & 0 & \frac{\partial N_{i}}{\partial y} & \frac{\partial N_{i}}{\partial x} & 0 & 0 & 0 & 0 & 0 \\
0 & 0 & 0 & 0 & 0 & 0 & 0 & \frac{\partial N_{i}}{\partial x} & 0 \\
0 & 0 & 0 & 0 & 0 & 0 & 0 & 0 & \frac{\partial N_{i}}{\partial y} \\
0 & 0 & 0 & 0 & 0 & 0 & 0 & \frac{\partial N_{i}}{\partial y} & \frac{\partial N_{i}}{\partial x} \\
0 & 0 & \frac{\partial N_{i}}{\partial x} & N_{i} & 0 & 0 & 0 & 0 & 0 \\
0 & 0 & \frac{\partial N_{i}}{\partial y} & 0 & N_{i} & 0 & 0 & 0 & 0 \\
0 & 0 & 0 & 0 & 0 & 2 N_{i} & 0 & 0 & 0 \\
0 & 0 & 0 & 0 & 0 & 0 & 2 N_{i} & 0 & 0 \\
0 & 0 & 0 & 0 & 0 & 0 & 0 & 3 N_{i} & 0 \\
0 & 0 & 0 & 0 & 0 & 0 & 0 & 0 & 3 N_{i}
\end{array}\right]
$$

The shape function of stiffener can be obtained by substituting $\xi=R, \eta=S$ into the shape function of plate element (Fig. 2). 


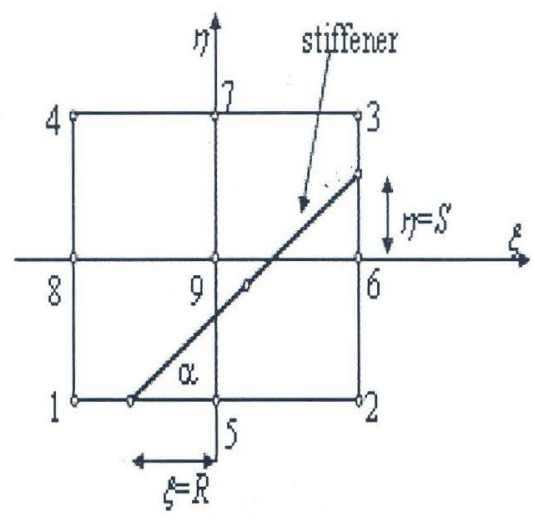

Fig. 2. Stiffened plate element

\subsection{Transformation matrix}

If we consider that the x-stiffener is attached to the lower side of the plate, conditions of displacement compatibility along their line of connection can be written as

$$
e_{x s}=\frac{t_{p}}{2}+\frac{t_{x s}}{2} ; e_{x s}^{*}=\left(\frac{t_{p}}{2}\right)^{2}+\left(\frac{t_{x s}}{2}\right)^{2} ; e_{x s}^{* *}=\left(\frac{t_{p}}{2}\right)^{3}+\left(\frac{t_{x s}}{2}\right)^{3} ; q_{x s i}=T_{x s} q_{p i},
$$

where

$$
T_{x s}=\left[\begin{array}{ccccccccc}
1 & 0 & 0 & -e_{x s} & 0 & -e_{x s}^{*} & 0 & -e_{x s}^{* *} & 0 \\
0 & 1 & 0 & 0 & 0 & 0 & 0 & 0 & 0 \\
0 & 0 & 1 & 0 & 0 & 0 & 0 & 0 & 0 \\
0 & 0 & 0 & 1 & 0 & 0 & 0 & 0 & 0 \\
0 & 0 & 0 & 0 & 1 & 0 & 0 & 0 & 0 \\
0 & 0 & 0 & 0 & 0 & 1 & 0 & 0 & 0 \\
0 & 0 & 0 & 0 & 0 & 0 & 1 & 0 & 0 \\
0 & 0 & 0 & 0 & 0 & 0 & 0 & 1 & 0 \\
0 & 0 & 0 & 0 & 0 & 0 & 0 & 0 & 1
\end{array}\right]
$$

The nodal displacement vector $q_{x s}$ can be written as $q_{x s}=T q_{p}$, where

$$
T=\left[\begin{array}{ccccccccc}
T_{x s} & 0 & 0 & 0 & 0 & 0 & 0 & 0 & 0 \\
0 & T_{x s} & 0 & 0 & 0 & 0 & 0 & 0 & 0 \\
0 & 0 & T_{x s} & 0 & 0 & 0 & 0 & 0 & 0 \\
0 & 0 & 0 & T_{x s} & 0 & 0 & 0 & 0 & 0 \\
0 & 0 & 0 & 0 & T_{x s} & 0 & 0 & 0 & 0 \\
0 & 0 & 0 & 0 & 0 & T_{x s} & 0 & 0 & 0 \\
0 & 0 & 0 & 0 & 0 & 0 & T_{x s} & 0 & 0 \\
0 & 0 & 0 & 0 & 0 & 0 & 0 & T_{x s} & 0 \\
0 & 0 & 0 & 0 & 0 & 0 & 0 & 0 & T_{x s}
\end{array}\right]
$$




\subsection{Virtual work}

Using the principle of virtual work, the equilibrium equations can be expressed as

$$
\begin{aligned}
& \sum_{N_{p}} \int_{A} \partial \varepsilon_{p}^{0 T} \sigma_{p}^{0} d A+\sum_{N_{x s}} \int_{l} \partial \varepsilon_{x s}^{0 T} \sigma_{x s}^{0} d x+\sum_{N_{p}} \int_{V p} \dot{q}_{p}^{T} \rho_{p} \dot{q}_{p} d V+\sum_{N_{x s}} \int_{V s} \dot{q}_{x s}^{T} \rho_{x s} \dot{q}_{x s} d V_{x s} \\
& =\sum_{N_{p}} \int_{A} \partial \phi_{p}^{T} q d A+\sum_{N_{p}} \partial \phi_{p}^{T} P
\end{aligned}
$$

Substituting Eqs. (3), (5), (6), (7) into (14) this equation can be expressed in terms of plate nodal displacements as

$$
\begin{aligned}
& \sum_{N_{p}} \int_{A} \partial q_{p}^{T}\left[B_{p}^{T} D_{p} B_{p}\right] q_{p} d A+\sum_{N_{x s}} \int_{l} \partial q_{p}^{T}\left[T_{x s}^{T} B_{x s}^{T} D_{x s} B_{x s} T_{x s}\right] q_{p} d x \\
& +\sum_{N_{p}} \int_{A} \partial \dot{q}_{p}^{T}[N(r, s)]^{T}[m][N](r, s) \dot{q}_{p} d A+\sum_{N_{x s}} \int_{A} \partial \dot{q}_{x s}^{T}[N]^{T}[m][N] \dot{q}_{x s} d A \\
& =\sum_{N_{p}} \int_{A} \partial q_{p}^{T} N(r, s)^{T} q d A+\sum_{N_{p}} \partial q_{p}^{T} N(r, s)^{T} P
\end{aligned}
$$

or

$$
\begin{aligned}
& \sum_{N_{p}} \partial q_{p}^{T} K_{p} \delta_{p}+\sum_{N_{x s}} \partial q_{p}^{T} K_{x s} q_{p}+\sum_{N_{p}} \partial \dot{q}_{p}^{T} M_{p} \dot{q}_{p}+\sum_{N_{x s}} \partial \dot{q}_{x s}^{T} M_{x s} \dot{q}_{x s} \\
& =\sum_{N_{p}} \int_{A} \partial q_{p}^{T} N(r, s)^{T} q d A+\sum_{N_{p}} \partial q_{p}^{T} N(r, s)^{T} P
\end{aligned}
$$

where $K_{p}=\int_{A} B^{T} D B d A$ is the plate element stiffness matrix

$$
K_{x s}=T^{T}\left[\int_{l} B^{T} T_{s}^{T} D_{s} T_{s} B d x\right] T
$$

is the stiffener element stiffness in which $B=B_{1} B_{2} \ldots B_{9}$.

The stiffness matrix of a stiffened plate element can be written as

$$
K_{s p}=K_{p}+\sum_{i=1}^{n s} K_{s}
$$

The mass matrix of a stiffened plate element:

$$
M_{s p}=M_{p}+\sum_{i=1}^{n s} M_{s}
$$

where $n s$ is the number of stiffeners in the plate element 


$$
\begin{gathered}
{[m]=\left[\begin{array}{ccccccccc}
I_{0} & 0 & 0 & I_{1} & 0 & I_{2} & 0 & I_{3} & 0 \\
0 & I_{0} & 0 & 0 & I_{1} & 0 & I_{2} & 0 & I_{3} \\
0 & 0 & I_{0} & 0 & 0 & 0 & 0 & 0 & 0 \\
I_{1} & 0 & 0 & I_{2} & 0 & I_{3} & 0 & I_{4} & 0 \\
0 & I_{1} & 0 & 0 & I_{2} & 0 & I_{3} & 0 & I_{4} \\
I_{2} & 0 & 0 & I_{3} & 0 & I_{4} & 0 & I_{5} & 0 \\
0 & I_{2} & 0 & 0 & I_{3} & 0 & I_{4} & 0 & I_{5} \\
I_{3} & 0 & 0 & I_{4} & 0 & I_{5} & 0 & I_{6} & 0 \\
0 & I_{3} & 0 & 0 & I_{4} & 0 & I_{5} & 0 & I_{6}
\end{array}\right] \quad \text { where } I_{i}=\sum_{l=1}^{n} \sum_{h_{l}}^{h_{l+1}} z^{i} \rho_{l} d z, i=0,1, \ldots, 6} \\
\\
{\left[M^{e}\right]=\int_{-1}^{+1+1}[N]^{T}[m][N] \operatorname{det}[J] d \xi d \eta .}
\end{gathered}
$$

External load vector, evaluated at $z= \pm h / 2$

$$
\left\{f^{e}\right\}=\int_{-1}^{+1} \int_{-1}^{+1}[N]^{T}[Z]^{T}\{p\} \operatorname{det}[J] d \xi d \eta .
$$

We obtain the system of equations as following:

$$
[M]\{\ddot{q}\}+[K]\{q\}=\{F\} .
$$

From the equation system, let $\{F\}=0$ we have the equation of the free vibration problem:

$$
[M]\{\ddot{q}\}+[K]\{q\}=0
$$

and if neglect acceleration, we have the equation for static problem

$$
[K]\{q\}=\{F\}
$$

\section{NUMERICAL RESULTS}

\subsection{Free vibration of stiffened laminated composite plates}

Example 1.' Validation of the proposed model

In order to validate the proposed model, we consider the same example studied by Satish Kumar Y.V. and Madhujit Mukhopadhyay [7]. In this example, the natural frequencies of cross-stiffened laminated plate under different boundary conditions were calculated. The geometric parameters are: $a=b=254 \mathrm{~mm}, h=12.7 \mathrm{~mm}, d_{s x}=d_{s y}=25.4$ $\mathrm{mm}, b_{s x}=b_{s y}=6.35 \mathrm{~mm}$ (Fig. 3), where: $d_{s x}, b_{s x}$ are depth and width of the $x$-direction stiffener; $d_{s y}, b_{s y}$ are depth and width of the $y$-direction stiffener.

Graphite/epoxy properties: $E_{1}=144.8 \mathrm{GPa}, E_{2}=9.67 \mathrm{GPa}, G_{12}=G_{13}=4.14 \mathrm{GPa}$, $G_{23}=3.45 \mathrm{GPa}, \nu_{12}=0.3, \rho=1389.23 \mathrm{~kg} / \mathrm{m}^{3}$. 


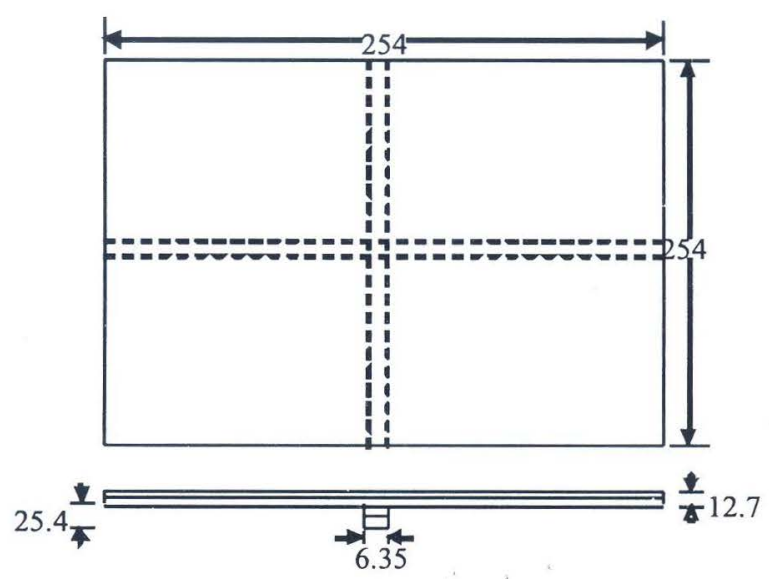

Fig. 3. Two cross stiffeners laminated composite plate

The four first natural frequencies are calculated and shown in the Table 1.

Table 1. Natural frequencies $(\mathrm{Hz})$ of $\left(0^{0} / 90^{\circ}\right) 2$ cross stiffeners plate

\begin{tabular}{|c|c|c|c|c|c|c|c|c|}
\hline \multirow{2}{*}{$\mathrm{BC}$} & \multirow{2}{*}{$\begin{array}{c}\text { Mode } \\
\text { no }\end{array}$} & \multicolumn{5}{|c|}{$\left[0^{\circ} / 90^{\circ}\right]$} & \multirow{2}{*}{ Modes } & \\
\hline & & [7] & [8] & [9] & FSDT & HSDT & & \\
\hline \multirow{4}{*}{ SSSS } & 1 & 1076.0 & 961.81 & 1092.64 & 1053.6 & 1039.8 & & \\
\hline & 2 & 2059.6 & 1954.41 & 1837.04 & 2083.7 & 2099.3 & & 1 \\
\hline & 3 & 2302.7 & 2325.41 & 2491.85 & 2327.6 & 2346.5 & & \\
\hline & 4 & 2635.8 & 2641.18 & 2654.51 & 2556.9 & 2492.5 & & \\
\hline \multirow{4}{*}{$\mathrm{CCCC}$} & 1 & 1666.5 & 1583.50 & 1753.79 & 1609.5 & 1559.4 & & 2 \\
\hline & 2 & 2929.2 & 2831.53 & 2716.65 & 2926.3 & 2924.0 & & \\
\hline & 3 & 3140.1 & 3165.27 & 3319.93 & 3141.2 & 3141.8 & & \\
\hline & 4 & 3666.3 & 3634.62 & 3686.53 & 3639.2 & 3618.5 & & 3 \\
\hline \multirow{4}{*}{ CCSS } & 1 & 1445.8 & 1342.1 & 1468.82 & 1427.5 & 1413.5 & & \\
\hline & 2 & 2107.7 & 2101.6 & 2029.11 & 2083.9 & 2065.8 & & \\
\hline & 3 & 3054.0 & 3024.58 & 3074.45 & 2896.7 & 2763.7 & & 4 \\
\hline & 4 & 3196.8 & 3211.27 & 3212.13 & 3209.9 & 3220.2 & & \\
\hline
\end{tabular}

From the Table 1, we can see that the natural frequencies of a plate with ratio of $a / h=20$ calculated by finite element method based on the first-order and higher-order displacement theory using nine-noded isoparametric element are in good agreement with the results published by other authors, especially, with [7], in which Kumar, Mukhopadhyay used 6-noded triangular element and based on the first-order theory. The natural frequencies of the stiffened laminated composite plates modeled by HSDT are lower than that of one based on FSDT.

Example 2. Effect of the locations of double stiffeners.

Next, we consider the free vibration of parallel-stiffened laminated plate with two $y$ stiffeners placed in different locations shown in Fig. 4 under clamped boundary conditions.

The geometric parameters and material properties are the same in example 1 . The results are shown in the Table 2. 


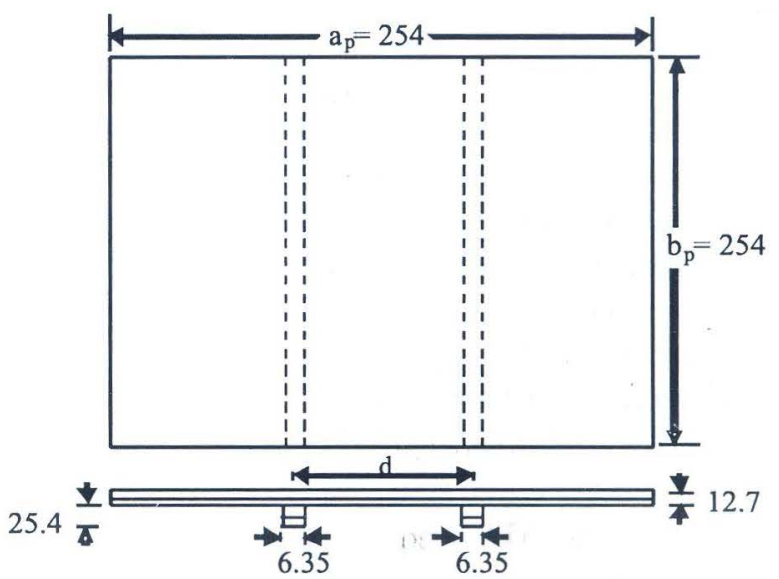

Fig. 4. Two $y$-stiffeners laminated composite plates

Table 2. Natural frequencies of two $y$-stiffeners plates $\left(0^{0} / 90^{\circ}\right)$

\begin{tabular}{|c|c|c|c|c|}
\hline \multirow{2}{*}{$\mathrm{d} / \mathrm{a}_{p}$} & \multicolumn{4}{|l|}{ Frequencies of 4 modes $(\mathrm{Hz})$} \\
\cline { 2 - 5 } & 1 & 2 & 3 & 4 \\
\hline 0.2 & 1913.6 & 2765.3 & 3721.2 & 3973.3 \\
\hline 0.4 & 1729.2 & 2871.9 & 3360.6 & 4378.7 \\
\hline 0.6 & 1510.6 & 2798.9 & 2922.9 & 4163.6 \\
\hline 0.8 & 1407.6 & 2698.7 & 2730.9 & 3746.0 \\
\hline
\end{tabular}

The frequencies in the Table 2 show that when the location of stiffeners becomes farther from the center line, the frequency of the lowest four modes goes up and down. Compared with others, the first frequency is biggest in case $d / a_{p}=0.2$ but the forth frequency is biggest in case $d / a_{p}=0.4$.

Example 3. Effect of number of layers and orientation angle of fibers

Table 3. Natural frequencies of two $y$-stiffeners plate with different number of layers

\begin{tabular}{|c|c|c|c|c|c|}
\hline Boundary & Mode & \multicolumn{4}{|c|}{ Number of layers and fibers } \\
\cline { 2 - 6 } condition & no & $0^{0} / 90^{0}$ & $0^{0} / 90^{0} / 90^{0} / 0^{0}$ & $0^{0} / 45^{0}$ & $0^{0} / 45^{0} / 45^{0} / 0^{0}$ \\
\hline \multirow{4}{*}{ SSSS } & 1 & 795.0 & 1205.9 & 833.4 & 1178.0 \\
\cline { 2 - 6 } & 2 & 1593.7 & 2647.0 & 1860.5 & 2646.1 \\
\cline { 2 - 6 } & 3 & 2272.0 & 2846.2 & 2162.8 & 2700.5 \\
\cline { 2 - 6 } & 4 & 2702.5 & 3758.9 & 2889.5 & 3179.2 \\
\hline \multirow{4}{*}{ CCCC } & 1 & 1478.4 & 2018.0 & 1496.3 & 1985.4 \\
\cline { 2 - 6 } & 2 & 2359.9 & 3458.2 & 2550.0 & 3341.0 \\
\cline { 2 - 6 } & 3 & 3016.0 & 3480.0 & 2800.6 & 3457.9 \\
\cline { 2 - 6 } & 4 & 3597.5 & 4543.9 & 3601.6 & 4470.2 \\
\hline \multirow{4}{*}{ CCSS } & 1 & 1037.8 & 1654.9 & 1192.2 & 1658.1 \\
\cline { 2 - 6 } & 2 & 2065.1 & 3048.0 & 2320.9 & 2991.3 \\
\cline { 2 - 6 } & 3 & 2378.0 & 3204.3 & 2420.2 & 3217.1 \\
\cline { 2 - 6 } & 4 & 3063.8 & 4223.6 & 3278.1 & 4191.0 \\
\hline
\end{tabular}


Consider the free vibration of parallel stiffened composite plates which have the same geometric parameters such as length, width, thickness and depth but they have different number of layers. The geometric parameters and material properties are the saine in example 2. The stiffeners are located at $x=a / 3$ and $x=2 a / 3$.

It is seen from the Table 3 . that the frequencies of 4 layers plates are bigger than the frequencies of 2 layers plates in all case of boundary conditions.

Example 4. Effect of $a / h$ ratio

In this example, we consider the effect of $a / h$ ratio on the natural frequencies. The geometric parameters and material properties of parallel stiffened plates are the same in example 3 with the ratio $a / h=10,20,50$ and 100. Structure is under the clamped boundary condition.

When the ratio $a / h$ goes up, the frequencies of parallel stiffened plates goes down. Results are shown in the Table 4.

Table 4. Frequencies of two $y$-stiffeners plates with different $a / h$ ratio

\begin{tabular}{|c|c|c|c|c|c|}
\hline \multirow{2}{*}{$\begin{array}{c}\text { Boundary } \\
\text { condition }\end{array}$} & Mode & \multicolumn{4}{|c|}{$0^{0} / 45^{0}$} \\
\cline { 3 - 6 } & no & $\mathrm{a} / \mathrm{h}=10$ & $\mathrm{a} / \mathrm{h}=20$ & $\mathrm{a} / \mathrm{h}=50$ & $\mathrm{a} / \mathrm{h}=100$ \\
\hline \multirow{3}{*}{$\mathrm{CCCC}$} & 1 & 2254.2 & 1496.3 & 1092.6 & 1024.5 \\
\cline { 2 - 6 } & 2 & 3766.9 & 2550.0 & 1377.3 & 1129.9 \\
\cline { 2 - 6 } & 3 & 4101.8 & 2800.6 & 2194.7 & 1407.3 \\
\cline { 2 - 6 } & 4 & 5184.3 & 3601.6 & 2483.3 & 1553.4 \\
\hline
\end{tabular}

\subsection{Bending behaviour of stiffened laminated composite plates}

\section{Example 5. Effect of the locations of stiffeners and fibers}

In this example, we calculate the deflection of stiffened composite plates. The geometric parameters and material properties are the same in the example 1 . The plate is clamped and under the bending load $q=-10^{6} \mathrm{~N} / \mathrm{m}^{2}$.

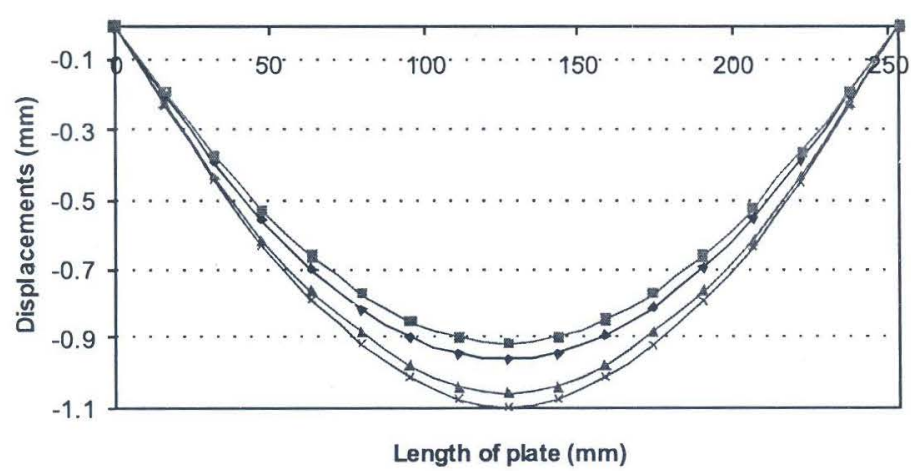

$\leftrightarrow$ Case A $\rightarrow$ Case B $\leftrightarrow$ Case C $*$ Case D

Fig. 5. Deflection of 2 cross and $2 y$-stiffeners composite plates

Case A: 2 cross stiffener, both plate and stiffener have 4 layers $\left(0^{0} / 90^{0} / 90^{0} / 0^{0}\right)$ Case B: 2 cross stiffener, both plate and stiffener have 4 layers $\left(0^{0} / 45^{0} / 45^{0} / 0^{0}\right)$ 
Case C: $2 y$-stifíeners, both plate and stiffener have 4 layers $\left(0^{0} / 90^{\circ} / 90^{\circ} / 0^{0}\right)$

Case D: $2 y$-stiffeners, both plate and stiffener have 4 layers $\left(0^{0} / 45^{0} / 45^{0} / 0^{0}\right)$

The deflection of the 2 parallel stiffened plates is bigger than that of 2 cross stiffened plate. In case of 2 parallel stiffened plate, the plate with the fiber angle $0^{0} / 45^{0} / 45^{0} / 0^{0}$ is harder than the plate with the fiber angle $0^{0} / 90^{\circ} / 90^{\circ} / 0^{0}$, but in case of 2 cross stiffened plate, the plate with the fiber angle $0^{0} / 90^{\circ} / 90^{\circ} / 0^{0}$ is harder than the plate with the fiber angle $0^{0} / 45^{0} / 45^{0} / 0^{0}$. The orientation angle of fiber and location of stiffeners influence on the stiffness of the stiffened laminated composite plate.

Example 6. Effect of a/h ratio

Consider the effect of $a / h$ ratio on the deflection of doubly stiffened laminated composite plates. The geometric parameters and material properties of parallel stiffened plates are the same as in example 1 with the ratio $a / h=10,20 ; 50$ and 100 . Structure is under the clamped boundary condition and bending load $q=-10^{6} \mathrm{~N} / \mathrm{m}^{2}$. Fig. 6 shows the deflections at center line along to $x$-axis of the plates.

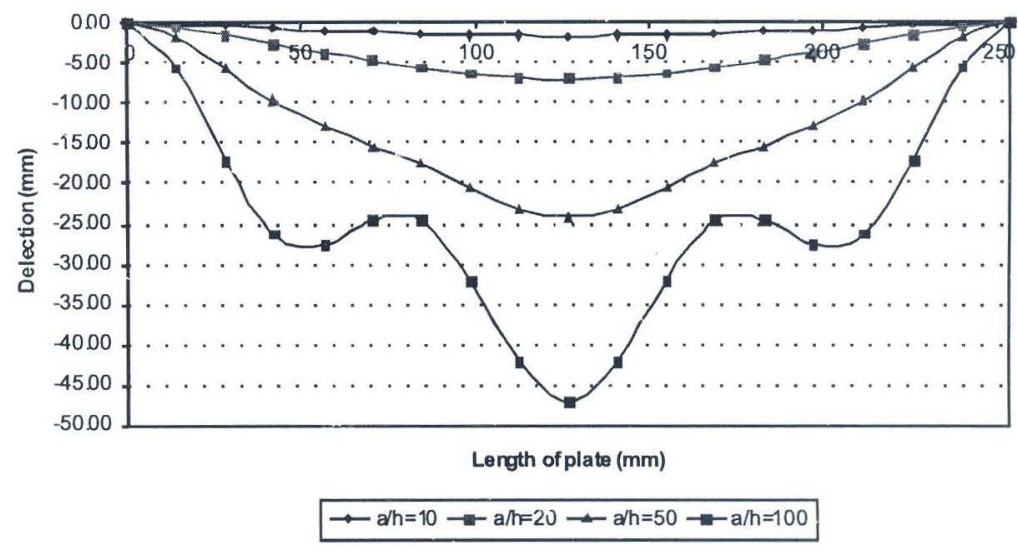

Fig. 6. Deflection of 2 parallel stiffened composite plates with different $a / h$ ratio

From Table 4 and Fig. 6 , we can see that $a / h$ ratio have a big influence on the frequencies and deflections of stiffened laminated composite plates. The thin stiffened laminated composite plates have lower frequencies and bigger deflections than the thick ones and conversely. The proposed model can apply for both thick and thin stiffener stiffened laminated composite plates.

\section{CONCLUSION}

In the present study, a finite elemerit model based on higher-order displacement theory for analysis of the stiffened laminated composite plate has been proposed.

Some problems such as effect of location, effect of number of layers and fibers and effect of $a / h$ ratio on the natural frequencies and deflections of stiffened laminated composite plates have been investigated. The change of location, number of layers and $a / h$ ratio have influence on the natural frequencies and deflections of stiffened plates. Therefore, the number of layers, fiber orientation angle and location of the stiffener in stiffened plates should be selected properly to control the specific frequency and deflection. 
By using direct finite element, the model can use to analysis of stresses at any point in the plates as well as in the stiffener. $08.0 \%$.

This work is sponsored by Ministry of Science and Technology and project QGTD

\section{REFERENCES}

1. T. Wah, Vibration of stiffened plates 15 (1964) 285-298, Aero Quart.

2. M. T. Ahmadian and M. S. Zangened, Application of super elements to free vibration analysis of laminated stiffened plates, Journal of Sound and Vibration 259 (5) (2003) 1243-1252.

3. M. D. Olson and C. R. Hazell, Vibration studies on some integral rib-stiffened plates, J. Sound Vibration 50 (I) (1977) 43-61.

4. M. Kolli and K. Chandrashekharat, Finite element analysis of stiffened laminated plates under transverse loading, Composites Science and Technology 56 (1996) 1355-1361.

5. K. C. Biswal, A. K. Ghosh, Finite element analysis for stiffened laminated plates using higher order shear deformation theory, Computers and Structures 53 (1994) 161 - 171.

6. Gangadhara Prusty, Linear static analysis of hat-stiffened laminated shells using finite elements, Finite element in analysis and design 39 (2003) 1125 - 1138.

7. Y. V. Satish Kumar, Madhujit Mukhopadhyay, A new triangular stiffened plate element for laminate analysis, Composites Science and Technology 60 (2000) 935 - 943.

8. K. Chandrasekhara, M. Kolli, Free vibration of eccentrically stiffened laminated plates, Journal of Reinforced Plastics and Composites 16 (10) (1997) 884 - 902.

9. Tran Ich Thinh, Composite Materials- Mechanics and Calculation of Structures, (1994) GD Publisher (In Vietnamese).

10. Tran Ich Thinh, Tran Huu Quoc, Static and Dynamic Analysis of Stiffened Composite Plates by FEM, Proceedings of the $8^{\text {th }}$ National Conference on Mechanics, 2 (2007), Bach Khoa Publisher (In Vietnamese).

Received June 25, 2008

\section{PHÂN TÍCH TÂM COMPOSITE LỚP CÓ GÂN GIA CƯỜNG BẰNG PHƯƠNG PHÁP PTHH DỰA TRÊN LÝ THUYẾT CHUYỂN VỊ BẬC CAO}

Bài báo sử dụng mô hình phần tử hữu hạn dựa trên lý thuyết chuyển vị bậc cao để phân tích tấm composite lớp có gân gia cường. Mồ hình có thể sử dụng để phân tích cả tấm dầy và tấm mỏng do trong công thức thiết lập có kể đến ảnh hưởng của biến dạng cắt ngang. Phần tử tấm-gân là sự kết hợp của một phần tử tấm với một hoặc nhiều phần tử gân. Chuyển vị của phần tử gân được nội suy thông qua chuyển vị của phần tử tấm chứa nó, do đó, phần tử tấm chấp nhận số gân bất kỳ và gân có hướng tuỳ ý trong nó. Kết quả tính toán tần số dao động tự do và chuyển vị của tấm composite lớp có gân gia cường khi chịu tải trọng uốn bằng mô hình nói trên rất tương đồng với một số kết quả đã công bố của các tác giả khác. 